\title{
Board 35: An Integrated Program for Recruitment, Retention, and Gradua- tion of Academically Talented Low-Income Engineering Students
}

\author{
Prof. Houshang Darabi, University of Illinois, Chicago
}

Dr. Houshang Darabi is an Associate Professor of Industrial and Systems Engineering in the Department of Mechanical and Industrial Engineering (MIE) at the University of Illinois at Chicago (UIC). Dr. Darabi is the recipient of multiple teaching and advising awards including the UIC Award for Excellence in Teaching (2017), COE Excellence in Teaching Award (2008, 2014), UIC Teaching Recognitions Award (2011), and the COE Best Advisor Award $(2009,2010,2013)$. Dr. Darabi is an ABET IDEAL Scholar and has led the MIE Department ABET team in two successful accreditations (2008 and 2014) of Mechanical Engineering and Industrial Engineering programs. Dr. Darabi has been the lead developer of several educational software systems as well as the author of multiple educational reports and papers. Dr. Darabi's research group uses Big Data, process mining, data mining, Operations Research, high performance computing, and visualization techniques to achieve its research and educational goals. Dr. Darabi's research has been funded by multiple federal and corporate sponsors including the National Science Foundation, and National Institute of Standards and Technology.

\section{Dr. Peter C Nelson, University of Illinois at Chicago}

Peter Nelson was appointed Dean of the University of Illinois at Chicago's (UIC) College of Engineering in July of 2008. Prior to assuming his deanship, Professor Nelson was head of the UIC Department of Computer Science. In 1991, Professor Nelson founded UIC's Artificial Intelligence Laboratory, which specializes in applied intelligence systems projects in fields such as transportation, manufacturing, bioinformatics and e-mail spam countermeasures. Professor Nelson has published over 80 scientific peer reviewed papers and has been the principal investigator on over $\$ 30$ million in research grants and contracts on issues of importance such as computer-enhanced transportation systems, manufacturing, design optimization and bioinformatics. These projects have been funded by organizations such as the National Institutes of Health, the National Science Foundation, the National Academy of Sciences, the U.S. Department of Transportation and Motorola. In 1994-95, his laboratory, sponsored by the Illinois Department of Transportation, developed the first real-time traffic congestion map on the World Wide Web, which now receives over 100 million hits per year. Professor Nelson is also currently serving as principal dean for the UIC Innovation Center, a collaborative effort between the UIC Colleges of Architecture, Design and the Arts; Business Administration; Medicine and Engineering.

Mrs. Rezvan Nazempour

Dr. Renata A Revelo, University of Illinois, Chicago

Renata A. Revelo is a Clinical Assistant Professor in the department of Electrical and Computer Engineering at the University of Illinois at Chicago. She earned her B.S. and M.S. in Electrical and Computer Engineering and her Ph.D. in Education Organization and Leadership from the University of Illinois.

\section{Prof. Ludwig C. Nitsche, University of Illinois at Chicago}

Ludwig C. NItsche completed bachelor's degrees in chemical engineering and mathematics at the University of Minnesota (1984) and a Ph.D. in chemical engineering at MIT (1989) before embarking on a NSF-NATO Postdoctoral Fellowship at the University of Cambridge, UK. He joined the UIC Chemical Engineering faculty in 1991, and has research interests in fluid mechanics, transport phenomena, applied mathematics and computer simulations - with applications in drug delivery technology.

Prof. Jeremiah Abiade 


\section{An Integrated Program for Recruitment, Retention, and Graduation of Academically Talented Low-Income Engineering Students}

In this paper, we summarize the poster presented at the NSF Grantees Poster Session that provides an overview of the S-STEM program. The S-STEM program at the University of Illinois at Chicago (UIC) began in 2017 and was developed to provide financial, academic, professional, and social support to incoming engineering students who are low-income and high achieving. The duration of the grant is five years. This paper summarizes the activities in the first 18 months of the project and the activities projected for the remainder of the project.

The objectives of this project are to 1) enhance students' learning by providing access to extra and co-curricular experiences, 2) create a positive student experience through mentorship, and 3) ensure successful student placement in the STEM workforce or graduate school. S-STEM Scholars in this program received financial, academic, professional, and social development via various evidence-based activities integrated throughout four years and starting with the summer prior to starting at the university. These activities include a summer bridge program, a freshman engineering success program, an introduction to engineering design course, a guaranteed paid internship program, a service-learning project, two professional development seminars, and an enhanced capstone experience. In addition, students are supported by peer, faculty, and industry mentors.

\section{Motivation}

The challenge of recruiting and graduating low-income engineering students is multi-faceted. Of particular importance to the University of Illinois at Chicago as a Minority Serving Institution, is that racial and ethnic minoritized are often also low-income students. Solutions have focused primarily on broadening access via outreach, aggressive recruitment and remediation-based interventions to retain these students to graduation. However, low-income, racial and ethnic minoritized groups and women continue to be underrepresented in engineering, despite considerable funding and individual and institutional effort. For the United States to remain a global leader in the STEM fields that require engineering training, the issue of underrepresentation must be addressed.

\section{Institutional Context}

UIC is a research-intensive, urban, Minority Serving Institution and also has the designations of Hispanic Serving Institution and Asian American Native American Pacific Islander Serving Institution. The College of Engineering (COE) at the UIC serves a diverse student population from various ethnic and economic backgrounds. Ten majors are offered within the College of Engineering, among which eight are ABET accredited. Approximately, 52\% of University of Illinois at Chicago and COE students are eligible for the Pell Grants and therefore considered lowincome.

The average one-year retention rate in the COE for first time freshmen-undergraduate students is $\sim 81 \%$ for students enrolled during Fall 2014 . The average six-year graduation rate is $65.3 \%$. The $\mathrm{COE}$ has seen steady improvements in its one-year retention rate and graduation rates over the last decade. 


\section{S-STEM Scholars Eligibility \& Selection}

Scholar selection was made on the basis of citizenship, academic talent, financial need, and a personal interview with the Award Committee members. The University Administration has developed a metric for admissions called Selection Index (SI), which represents the predicted first semester GPA (multiplied by 10) and ranges from 0 to 40. SI specific to the College of Engineering is calculated using a linear regression model with high school GPA and composite ACT as parameters, based on five preceding years of data on students. An SI score cutoff point will be used to qualify for the program. Also, to be eligible for the S-STEM scholarship, students had to be U.S. citizens or permanent residents and be eligible for the Federal Pell Grant.

Potential S-STEM Scholars were selected by the COE's Director of Admissions, who provided a list of applicants Sis within a target range for recruitment. This list was examined with the help of the Office of Student Financial Aid to determine the potential financial needs of each applicant. Applicants who met the listed qualifications were contacted in February and March of 2018. In the spring semester, 45 potential Scholars were interviewed by the Award Committee. The Award Committee consisted of all faculty members who were also investigators on the NSF grant that supports this work. During this interview, candidates were asked various questions guided by [1]. The purpose of the interview was to determine the motivation and maturity of each candidate.

After each interview, the Award Committee members scored each candidate on a rubric. After all interviews were completed, the committee convened to discuss their scores for each student. Also, considered during this selection process were level of financial need and the student's major. Based on the committee's input, 18 students were offered scholarships and all offers were accepted.

\section{S-STEM Scholars First Cohort}

The first cohort of S-STEM Scholars were recruited, interviewed, and selected in the first half of 2018. In total, there were 18 students that were selected for the first cohort of S-STEM Scholars. Aside from the support program provided, the Scholars received financial assistance, based on their individual need.

The first cohort of S-STEM Scholars represent nine engineering majors in the college. Out of 18, 8 are female and 10 are male. Eight students are first-generation college students. Two of the students identify as Black/African American and eight as Hispanic.

\section{Evidence-Based Activities}

To achieve our project objectives, we designed a comprehensive, interdisciplinary support program starting with the summer before the Scholars start university. All of the activities within the program are evidence-based activities that have been shown to be effective in the literature for this population of engineering students. Figure 1 below summarizes the activities on which this program is built. 
- Summer Bridge Program

- Fall 2018

-Freshman Engineering Success Program (ENG 100 and ENG 194)

- Spring 2019

-Introduction to Engineering Design

- Service Learning Program

-Spring ENG 499.1 Professional Development

- Fall 2021

-ENG 499.2 Professional Development

- Senior Design 1

- Spring 2021

-Senior Design 2

$\cdot$ EXPO

Figure 1- Timeline of Activities for the first Cohort

Since the grant is finishing its first year, we have completed only a few of the activities on the timeline shown above. Namely, the first cohort of S-STEM Scholars have gone through the Summer Bridge Program, Freshman Engineering Success Program, and part of the Mentorship Program. Lessons learned and feedback are discussed for the completed activities in the next section of this paper.

Summer Bridge Program. The Summer Bridge Program consists of a two-week, residential, and immersive experience designed to prepare S-STEM Scholars for transitioning into college and sustaining success throughout the undergraduate years, by fostering confidence, a sense of belonging, and trust. A pedagogical approach is adopted in which the following aspects are cultivated: academic success, peer and faculty mentorship, professional goals, community involvement, and emotional support.

The Summer Bridge Program takes a compound approach to encourage academic success for participants. Each scholar was immediately paired with a student ambassador. For Cohort 1 Scholars (recruited in Fall 2018), academically talented juniors and seniors who are leaders of professional societies serve as their student ambassadors. The student ambassadors for Cohort 2 Scholars (will be recruited in Fall 2019) will be S-STEM Scholars from Cohort 1.

Mentorship Program. A core component of the S-STEM Program is providing the students with access to peer, faculty, and industry mentors. During the Summer Bridge Program, students were assigned undergraduate ambassadors who served as mentors. The undergraduate ambassadors were engineering students in their second or third year of their studies. They were selected based on their involvement within their major (e.g., participating in a student organization) and their academic performance. The undergraduate ambassadors guided the 
Scholars through the Summer Bridge Program with academic, professional, and social questions as the Scholars became acquainted with the university and their major.

During the first semester at the university and immediately following the Summer Bridge Program, the Scholars were assigned faculty mentors from the academic department corresponding to the scholar's major. Faculty mentors were selected based on their positive engagement with undergraduate students and mentoring abilities. Faculty mentors were provided guidelines and a short presentation on mentoring in the first semester of the program. Advice and guidelines provided during the presentation were based on the text Adviser, Teacher, Role Model, Friend [2]. Mentoring meetings with faculty were required at least twice a semester and guiding forms and documents were provided for mentors to hold effective meetings with students. Students will be mentored by faculty throughout their undergraduate years at the university.

Freshman Engineering Success Program. Freshman Engineering Success Program (FESP) is a coordinated effort by the six engineering departments at the University of Illinois at Chicago to support first year students during their first fall semester. Faculty from each department lead the general sessions and organize the break-out sessions and mini-projects in their respective disciplines. In addition, interaction with local student chapters of engineering societies and junior/senior level teaching assistants is also provided to enhance early experiences and to encourage students to be self- directed in their educational planning process and overall academic success. One of the major components of FESP is a required engineering orientation course that is titled ENGR100.

ENGR100 is a required course for all incoming first year students to the COE at the University of Illinois at Chicago. It acclimates students to university support programs such as tutoring centers and career services, while at the same time introducing them to industry leaders and engineering professional societies. In addition to ENGR100, S-STEM Scholars were also required to take a complementary course to ENGR100, ENGR194.

ENGR194, as part of FESP, was offered for the first time in the Fall of 2018. This course was opened to all engineering students, including S-STEM Scholars. In Fall 2018, there were 39 students registered for ENGR194, 18 of those students were S-STEM Scholars. ENGR194 provided the opportunity to engage in activities such as interacting with professionals of various disciplines and cultural backgrounds in an informal environment and attending seminars and symposia on subjects including: engineering identity, engineering research, and careers in STEM. In addition, faculty involved with S-STEM, beyond those in the core investigators group, gave presentations on their fields and its relation to mathematics - loosely following other successful engineering math models [3]. Through ENGR194, students in the course were placed into mathematics study groups based on their courses.

Introduction to Engineering Design. Courses in which engineering design is taught, prior to the capstone project have been identified as best practice for retention in engineering [4] and an important improvement to the engineering curriculum (as cited in [5]). Introduction to Engineering Design is a multidisciplinary engineering design project-based course that is offered by the Mechanical and Industrial Engineering department. S-STEM Scholars majoring in Civil, Industrial, and Mechanical Engineering will take this course. S-STEM Scholars majoring in 
Bioengineering will take a parallel design course in their department. S-STEM Scholars majoring in Computer Science, Electrical, and Computer Engineering will be encouraged to take either Introduction to Engineering Design, or a Makerspace-based advanced manufacturing course offered by the college: ENGR 111/112 Engineering Practicum in Additive/Subtractive Manufacturing.

Guaranteed Paid Internship Program. Scholars will be encouraged to participate in the Guaranteed Paid Internship Program, GPIP, during the summer going into their sophomore year. GPIP is a novel, existing program within the college that guarantees qualified, academically talented students a paid internship or research opportunity as long as they commit to return to the College of Engineering the following fall semester.

Service Learning Project. During their second and third academic years, each semester, Scholars will have an opportunity to engage with the local community through a Service Learning Project (SLP). This existing community- oriented outreach activity, which is run through the University of Illinois at Chicago, not only provides students with a sense of pride and belonging through their efforts during the event, but this event also has a reflection component to allow Scholars to deeply connect with themselves and the community. At the end of each semester, Scholars will present their service learning project experience to their fellow Scholars, peers, and faculty during a Scholar appreciation event.

Professional Development Seminars. During the spring semester of their third year, SSTEM Scholars will enroll in the first course of a two-course sequence on Professional Development, 499.1. This course is a required course for all COE students that focuses on obtaining employment in a STEM field, as well as career development skills. Scholars will gain crucial knowledge and skills to becoming successful in not only obtaining a job, but also being successful in that job. During their final fall semester and to complement 499.1, S-STEM Scholars will enroll in a new course, 499.2, a professional development course with a focus on personal finance and job offer evaluation. The goal of this course is to ensure that S-STEM Scholars are adequately prepared for life after their undergraduate degree whether they choose to pursue a career in industry or graduate studies. Both courses will help students develop skills that are beneficial for placement in the STEM workforce.

Senior Design Capstone Projects. Senior Design is offered as a sequence of two courses and are required for graduation. Through this course sequence, S-STEM Scholars will enhance their engineering design skills and bring together the knowledge they will have received over the preceding four-five years. Their final designs will be presented at an engineering EXPO, a poster competition that is judged by the University of Illinois at Chicago Engineering Alumni and industry experts.

\section{Feedback and Lessons Learned from the First 18 months}

SBP Lessons Learned. Data collected from evaluation of the SBP indicated that the SSTEM Scholars' expectations were largely met by the various SBP activities. In other words, for most of the Scholars, the SBP was a valuable experience. As we mentioned before, the most important goals of this program were academic success, peer and faculty mentorship, professional goals, community involvement, and emotional support and we designed each component of the 
SBP to achieve these goals. The assessment data showed that the Scholars valued their experience as a whole and planned to utilize their new knowledge gained during the SBP as they matriculated at the University of Illinois at Chicago. We submitted another paper regarding the Summer Bridge Program 2018 and reported all lessons and experiences learned from the program.

FESP Lessons Learned. During the Fall 2018, for the first time we offered ENGR194 for S-STEM students. We created a survey to evaluate our performance during the course. Using the information, the team of investigators on the grant and the key personnel discuss the feedback received on each module of the course. During the discussion, the team decided whether each of them should be kept in the program, improved with minor or major changes, or substituted. The team also discussed aspects of each module such as the length of that and the content delivered.

Mentoring Program Lessons Learned. Selection of proactive faculty mentors and involvement from the investigators team has been key in ensuring that all Scholars' have access to resources and feel supported. While we have implemented structure for the mentoring program, a conversation among all the mentors to discuss how the mentoring sessions are going and check in with one another may be fruitful for strengthening of the program.

\section{Generation of Knowledge}

Educational research in the areas of engineering identity and self-efficacy is ongoing for this project. As of the submission of this paper, we have conducted engineering identity focused interviews with 16 Scholars and self-efficacy focused surveys with 18 Scholars. The data are being analyzed this year and a report on the findings will be disseminated at an educational conference in Fall of 2019.

\section{Conclusions}

While the S-STEM program is in its early stages, we have noted a few concluding points that encompass the process of the program development so far as well as the impact on the college. The recruitment process allowed number of qualified candidates to be identified since only students already admitted to the university were considered. The diversity of the S-STEM Scholars is reflective of the student diversity on campus and college demographics. Finally, the S-STEM grant has been used to leverage existing campus resources to provide comprehensive support for S-STEM Scholars.

\section{Acknowledgement}

Partial support for this work was provided by the National Science Foundation Scholarships in Science, Technology, Engineering, and Mathematics (S STEM) program under Award No. 1644182. Any opinions, findings, and conclusions or recommendations expressed in this material are those of the author(s) and do not necessarily reflect the views of the National Science Foundation.

\section{References}


[1] W. E. Sedlacek and H.-B. Sheu, "Academic success of Gates millennium scholars," Read. Equal Educ., vol. 20, pp. 181-197, 2004.

[2] I. of Medicine, N. A. of Sciences, and N. A. of Engineering, Adviser, Teacher, Role Model, Friend: On Being a Mentor to Students in Science and Engineering. 1969.

[3] N. W. Klingbeil, R. Mercer, K. S. Rattan, M. L. Raymer, and D. B. Reynolds, "Redefining engineering mathematics education at Wright State University," 2006.

[4] B. Yoder, "Going the distance in engineering education: Best practices and strategies for retaining engineering, engineering technology, and computing students," in American Society for Engineering Education, 2012.

[5] A. Johri and B. M. Olds, Cambridge handbook of engineering education research. Cambridge University Press, 2014. 